\title{
Examining the Relationship between Gender, Age, Education Level and Social Cognitive Factors in a Health Setting
}

\author{
Md. Nor Othman \\ Faculty of Business and Accountancy, University of Malaya \\ 50603 Lembah Pantai, Kuala Lumpur, Malaysia \\ Tel: 60-3-7967-3800 E-mail: mohdnor@um.edu.my \\ Sheau Fen Yap (Corresponding author) \\ School of Business, Monash University \\ Jalan Lagoon Selatan, Bandar Sunway, 46150 Selangor Darul Ehsan, Malaysia \\ Tel: 60-3-5514-6171 E-mail: crystal.yap@buseco.monash.edu.my \\ Yu Ghee Wee \\ Faculty of Entrepreneurship and Business, University Malaysia Kelantan \\ Karung Berkunci 36, Pengkalan Chepa \\ 16100 Kota Bharu, Kelantan, Malaysia \\ Tel: 60-9-771-7263 E-mail: yughee@umk.edu.my
}

Received: March 8, 2011 Accepted: April 6, 2011 doi:10.5539/ijbm.v6n9p79

The research is funded by Institute of Research Management and Monitoring (IPPP), University of Malaya (Grant Reference No. PS035/2007C)

\begin{abstract}
Most research on exercise is dominated in the West and is seldom featured in the marketing literature. Efforts in examining the demographic differences with respect to social cognitive factors contained in the Theory of Planned Behavior (TPB) have been largely neglected. This paper aims to examine the relationship between gender, age, education level and the TPB sub-components of attitude, subjective norm, and perceived behavioral control. Conducted in Malaysia, this study employs a cross-sectional survey administered to a quota sample of 512 general adults. A fit measurement model with adequate evidence of convergent and discriminant validity is established using confirmatory factor analysis. Overall, the results show that gender, age, and education do exert a certain level of influence on the social cognitive factors and the subjects' exercise behavior. The application of socio-cognitive approach to examine the exercise behavior yielded contributions in terms of theory, methodology, and practice.
\end{abstract}

Keywords: Exercise, Demographic, Social cognition, Theory of Planned Behavior, Public health promotion

\section{Introduction}

Issues related to health continue to invite much attention from the government and wide coverage from mass media due to the many illnesses which threaten human well-beings. The government and various stakeholders are drawn to monitor closely the subject of health because any ignorance, slight mismanagement or reactive as opposed to proactive measures, will bring negative impact on the socio-economic development of the country where productivity and performance of human capital are at stake. To ensure healthy living which is not plagued by any deadly diseases, Malaysian government have allocated a huge funding for the implementation of various health promotion and interventions (Health Facts in Malaysia, 2009). Such measures have successfully increased the level of awareness for health and the dire needs to stay fit, especially among urbanite and higher social class.

In the wake of such call, health-conscious groups create the demand for various health-related offerings and this new trend of consumerism subsequently spurs the emergence, growth and development of few industries. For 
instance, in the food and beverage industry, health-oriented key offerings such as low-fat, low cholesterol, low-sugar, and low-preservative foods are heavily promoted in the market. The consumer expenditures on health-related goods and health care services in Malaysia peaked RM10.6 million in 2009 (Euromonitor International, 2010). Another industry which witnessed an explosive growth fuelled by rising health awareness is the pharmaceutical industry. The Malaysian pharmaceutical market had been growing at $8 \%$ to $10 \%$ annually over the last decade (http://www.mopi.org.my). These major shifts in consumer buying patterns have greatly altered the way many marketers in the food, healthcare and medical services industry position their brands.

Despite increasing health awareness and numerous campaigns as well as initiatives to promote healthy living, Malaysians are experiencing some lifestyle changes due to socio-economic development, urbanization and market globalization. This has led to the prevalence of obesity and "lifestyle" related illnesses like diabetes, heart attack, and cancers (Omar, 2002). It has been projected based on the National Health Morbidity Survey (NHMS) that 2.99 million people will have heart disease by year 2010 and 3.56 million, subsequently in 2020 (Pang, 2006). Lately, Malaysia was ranked sixth among the Asian countries with the highest percentage of obese people (The Star, December 9, 2010). In view of the strong marketing implications of healthy living as well as the prevalence of lifestyle related health problems, a good understanding of factors contributing to healthy living behavior is therefore warranted.

\section{Theoretical Background}

Healthy living plays an important role in promoting physical health and social well-being (Bolton, Reed, Volpp, and Armstrong, 2008). Substantial research has clearly supported the role of regular exercise in promoting psychological and physical health (Paluska and Schwenk, 2000). Beyond individual health benefits, corporate and eventually the community as a whole benefited from regular exercise as well (Rütten, Röger, Abu-Omar and Frahsa, 2009). Despite the fact that various physical and psychological benefits of exercise are well documented and well publicized, the levels of physical inactivity are increasing worldwide (Bond and Batey, 2005). The health benefits of exercising as well as the prevalent sedentary lifestyle give a strong reason for the present study to look into the determinants of exercise behavior.

A solid model allows "the study of complex networks of variables, clear tests of hypotheses; and possible explanatory mechanisms for exercise behaviour" (Biddle and Nigg, 2000, p. 292), a sound theoretical foundation is therefore warranted. This study drew upon a popular social psychology model to explain health behavior - the Theory of Planned Behavior (TPB, Ajzen, 1991) as this model represents the most validated social cognitive framework behavioral prediction (Rivis and Sheeran, 2003). TPB is a belief-based social cognitive theory which posits that intention to perform a given behavior is the immediate antecedent of that behavior (Ajzen, 1991). In turn, intention is determined by three conceptually independent social cognitive variables [i.e., attitude, subjective norms and perceived behavioral control $(\mathrm{PBC})]$ which were originally measured as single concept (Armitage and Christian, 2003).

However, recent works suggest that these three constructs should each comprise of two specific components: (a) instrumental and affective attitude; (b) injunctive and descriptive norm; and (c) perceived control and self-efficacy. For instance, Rhodes, Blanchard and Matheson's (2006) study showed an additional explained variance of $11 \%$ to $36 \%$ when these social cognitive constructs were modeled as multi-components. Further, an empirical study by Hagger and Chatzisarantis (2005) also support the discriminant validity of the differentiated TPB measures. These findings seem to suggest a more superior measurement when the social cognitive predictors are modeled as multidimensional components.

Briefly, instrumental attitude is conceptualized as the subjects' favorable and unfavorable views towards the perceived benefit (e.g., improves physical health, relieve stress and promote relaxation) associated with performing exercise activities whilst affective attitude reflects the positive or negative feelings (e.g., enjoyment, pleasure, and satisfaction) towards exercise participation (Hagger and Chatzisarantis, 2005). While injunctive norm is referred to as a person's perceptions of normative influences in which the engagement of exercise activities is approved / expected / wanted by significant others; descriptive norm reflects the perceived social influences in which the exercise behavior is typically performed by significant others (Rhodes, Blanchard and Matheson, 2006). As for the PBC components, perceived control refers to the extent to which an individual has the necessary means and resources to exert control over the performance of exercise activities (e.g., personal control over behavior, appraisal of whether the behavior is completely up to the actor). The second component, perceived self-efficacy is conceptualized as one's perceived capability and self-confidence in their ability to engage in exercise (Hagger and Chatzisarantis, 2005).

A study on the exercise participation of 4,807 youths in Malaysia carried out in year 2006 revealed a lack of interest in youths to exercise and to participate in sports (Andres, 2006). Despite that this condition has detrimental effects as the low score for exercise participation indicates the health of youth would be affected in the long run, very few exercise research has been conducted in Malaysia. Much of these limited studies are commercial like survey or non-academic research lacked empirical and comprehensive analysis. Indeed, most of the exercise research is dominated in the West. 
Although work related to exercise behavior has received great attention in the health science, medicine, health and social psychology discipline in the Western literature, research on exercise seldom feature in the marketing literature (Adams and Mowen, 2005). Further, past studies built around the TPB have limitations for their dependence on convenience and undergraduate students or homogeneous groups such as patients / pregnant women, with little effort focus on samples drawn from the general population (Armitage and Christian, 2003). Lastly, a majority of TPB studies have focused on the key relationships between variables investigated. Efforts in examining demographic differences with respect to the social cognitive factors contained in the TPB have been largely neglected. These research gaps will be addressed in the present study.

\subsection{Exercise Behavior, Social Cognitive and Demographic Variables}

Many researchers have examined whether the TPB incorporates all the major predictors of intention and behavior (Armitage and Conner, 2001). One of the limitations of TPB is that factors like demographic variables are not being emphasized in TPB studies (Armitage and Christian, 2003). Indeed, Courneya, Bobick and Schinke (1999) argued that external factors like demographic variables are often neglected in the health domain. Specifically, very few studies have provided demographically related determinants of exercise behavior. Among these limited studies, Nies and Kershaw (2002) reported age and income to have significant effect on physical activity and health outcome. They concluded that the overall physical activity level among sedentary women tend to decrease as age increased; whereas income is related to physical activity performance positively.

\subsubsection{Gender Differences in Social Cognitive Factors and Exercise Behavior}

It is observed in the health literature that women tend to lead healthier living than men. For instance, in studies examining consumer healthy lifestyle behavior, $\mathrm{Ka} \mathrm{He}$, Kramer, Houser, Chomitz, and Hacker (2004) and Divine and Lepisto (2005) found female to be more likely to make healthy choices compared to their male counterparts. Similarly, Steptoe, Wardle, Vinck, Tuomisto, Holte, and Wichstrøm (1994) also found females to have higher ratings on health practices index than males. This justifies the inferences drawn that females tend to possess more positive attitudes towards exercise participation compared to males. Fontenelle and Zinkhan (1993) argued that males and females do have perceptual differences towards leisure activity. As exercise participation is a form of leisure activity that involved socialization, it is expected that males and females might have a different level of reference group influence.

With regards to the PBC components, Sylvia-Bobiak and Caldwell (2006) found in their active leisure study that male college students were more physically efficacious than female students. It is generally agreeable that males tend to be more likely to have greater exercise-related opportunities and resources and possess stronger motivations to exercise than females (Symons Downs, Graham, Yang, Bargainier, and Vasil, 2006). Further, Brickell, Chatzisarantis and Pretty's (2006) study reported that males scored significantly higher than females on the measures of exercise intention. Lastly, Rimal (2002) reported that female respondents exercised about $9 \%$ less often and tended to exercise fewer numbers of days in a week than males. Similarly, Grzywacz and Marks (2001) also found women to consistently exercise less frequently than men.

\subsubsection{Age Differences in Social Cognitive Factors and Exercise Behavior}

Studies that examine the age group differences in social cognitive factors have been largely neglected. Nigg, Lippke and Maddock (2009) examined whether the TPB framework operates equivalently across gender, age, and ethnic groups using a random sampling method $(\mathrm{n}=3533)$ and found no significant age difference in the global attitude and PBC concepts. However, it would be interesting to examine whether there exists any age differences in terms of specific attitude (i.e., instrumental and affective attitude) and PBC components (i.e., perceived control and self-efficacy). Theoretically, older people have relatively higher social needs and are more likely to conform to the opinions of the significant others (Morris and Venkatesh, 2000). When applied to exercise behavior, Nigg, Lippke and Maddock (2009) found that the younger samples view the subjective norm influence as less important than the older samples. These views seem to support the argument that older individuals are more susceptible to social influences when it comes to exercise participation.

In the U.S. context, it was reported that baby boomers are more likely to join fitness clubs, and more likely to adhere to exercise classes and participate in a variety of sports activities (Johnson, 1998). Also, in an analysis of several types of healthy lifestyle behaviors including exercise, Divine and Lepisto (2005) showed that an individual who lead a healthy lifestyle tend to be older. In contrary, Grzywacz and Marks (2001) and Piazza, Conrad and Wilbur (2001) found in their studies that young adults exercise more regularly and are less likely to be sedentary. These mixed findings lead the present research to look into the age differences in specific TPB components as well as the subjects' exercise behavior.

\subsubsection{Education Level Differences in Social Cognitive Factors and Exercise Behavior}

The notion that education has a positive association with health is well established (Ross and $\mathrm{Wu}, 1996$ ). Numerous studies have concluded that people who adopt a healthy lifestyle tend to be more educated (e.g., Ka He et al., 2004; Divine and Lepisto, 2005). Education level can influence an individual's perception and information processing regarding the health information they received (Grzywacz and Marks, 2001). Further, Grzywacz and Marks (2001) also argued that social status could be an important factor in determining the 
allocation of resources, opportunities, and constraints that may influence a person's health behaviors such as exercise. Therefore, it is possible that education has an association with a person's perception of control, self-efficacy, and attitudes towards exercise; this relationship also extend to the normative influence important others have on a person's decision to engage in exercise activities.

While Mohd Nordin, Shamsuddin, Jamaludin and Zulkafli (2003) found no significant association between education level and exercise behavior among women workers in an electronics factory located in an urban area in Malaysia, previous studies conducted in the Western context often demonstrate a positive link between education level and exercise behavior. For instance, in the exercise domain, Rimal (2002) found that subjects with at least a college level education exercise $5.95 \%$ more frequently than those without any college education. Grzywacz and Marks (2001) also found that people with higher education tended to participate more regularly in physical activity. Similarly, Marks and Lutgendorf (1999) also reported that more educated people are engaged in significantly higher levels of exercise.

It is worth noting that most of the past studies on exercise have been focused on the association between demographic variables such as age, gender, education level, occupation, income and exercise behavior or participation. However, no previous attempt has looked into the demographic differences in the social cognitive factors contained in the TPB model except for Nigg, Lippke and Maddock (2009) which was conducted in the West. Nigg, Lippke and Maddock's (2009) study merely focused on examining the relationship between selected demographic variables and the global concept of each of the TPB construct. However, these demographic variables may have different association with the specific TPB sub-components such as instrumental and affective attitude. Overall, this paper aims to close the research gaps by investigating the relationship between gender, age, education and the sub-components of attitude, subjective norm, and PBC comprehensively. Based on the above empirical and theoretical justifications, it is expected that there are gender, age, and education level differences in the instrumental and affective attitude, subjective and descriptive norm, perceived control and self-efficacy, the subjects' exercise intention as well as in their exercise behavior.

\section{Method}

A cross-sectional survey approach was adopted. This section provides a description of the research instrument design, sampling procedure and data collection technique.

\subsection{Research Instrument}

The survey instrument was translated from English into Malay and Chinese Language using the back-to-back translation method. There were a total of 40 questions measuring exercise intention and the three social cognitive factors. All the items were adapted from previously published work with necessary wording changes and were measured on a 7-point Likert-type scale ranging from "strongly disagree" to "strongly agree". Items measuring attitude and PBC components as well as exercise intention were adapted from Hagger and Chatzisarantis (2005) and Rhodes and Courneya (2003) while the items measuring subjective norm components were taken from Hagger and Chatzisarantis (2005). These items have indicated a satisfactory reliability in the past exercise studies among university students and employees (Hagger and Chatzisarantis, 2005) and cancer survivors (Rhodes and Courneya, 2003).

Exercise behavior was assessed using a previous validated research instrument - the Godin Leisure Time Exercise Questionnaire (GLTEQ; Godin and Shephard, 1985). GLTEQ is a simple, self-administered, validated, and reliable measure (Rhodes and Courneya, 2003). The GLTEQ has been popularly used to evaluate exercise behavior (e.g., Wilson, Rodgers, Fraser and Murray, 2004), physical activity (e.g., Rhodes, Blanchard, Matheson and Coble, 2006), exercise adherence and preferences (e.g., Courneya and Hellsten, 1998). Participants were asked to complete the GLTEQ which composed of three self-report items assessing the weekly frequency of strenuous, moderate, and mild levels of exercise during leisure time for periods of 15 minutes on an open scale. Based on predefined metabolic units (METs), a composite score was computed to measure the exercise behavior construct (Godin and Shephard, 1985). The GLTEQ has been modified to suit the local Malaysian context with the addition and deletion of some exercise activities. For instance, "cross country skiing" and "alpine skiing" activities have been excluded whilst popular activities like "Taichi" and "Qi gong" have been included in the mild exercise category.

Lastly, some background information of the respondents such as gender, age, ethnicity, religion, marital status, level of education, income, and occupation were also captured. The questionnaires were pre-tested using a sample size of 30 general adults (i.e. Faculty members, undergraduate and post-graduate students). Respondents were asked to evaluate the clarity of the wording, ease of comprehension, the level of language in terms of sensitivity, as well as length, format, and instructions for the entire survey in order to minimize ambiguities and communication errors. Based on the feedback from the respondents as well as from five experts in the area of Marketing, several corrections and modifications were made in terms of the wording, presentation and the structure of the questionnaire. Respondents who had participated in the pre-tests were not included in the main study. 


\subsection{Sampling Procedure and Data Collection Method}

Participants for the present study were general adults (18 to 55 years of age) recruited by student helpers employed from several colleges and universities. A lecturer-facilitator was employed to assist in the coordination of the data collection process. Each student helper was given 5 to 10 sets of questionnaires and they were instructed to collect data from various sources of respondents such as peers, neighbors, and relatives recruited through informal contact. A briefing on the research purposes, objectives, and procedures was provided to student helpers prior to data collection. As a token of appreciation for their assistance, a small gift in the form of a souvenir was given to each student helper.

It is recognized that data representativeness is one of the utmost important considerations in research so that the findings can be generalized to the larger population. However, due to the unavailability of an accurate sampling frame, and the main objective of this study was to derive theoretical generalizability as opposed to population generalizability (Calder, Philips and Tybout, 1982), the use of non-probability quota sampling was considered appropriate. To provide an adequate level of confidence in this study, a sample size of 600 respondents was targeted. Based on the composition of the total population of Malaysia, the study sets a 50-50 quota for gender and a, 50-30-20 quota for ethnic groups (Malay, Chinese, and Indian). The Indian group was set higher at 20\% compared to the national Census of $10 \%$ in order to capture an adequate number of Indian respondents. Exercise is an urban phenomenon (Ngui, 2005); it is thus justifiable for the present study to be conducted in the Klang Valley since it is the largest urban centre in Malaysia.

\section{Results and Discussions}

This section presents the findings of the survey. A total of 512 completed questionnaires were used for data analysis. The remaining questionnaires were not accepted on the grounds of: (1) incomplete response; (2) responses with little variance; (3) patterns of responses showed the respondent did not understand the content and/or instructions. These questionnaires with unsatisfactory responses were discarded. The Chi-square analysis showed no significant demographic differences between the usable and unusable responses.

Based upon Anderson and Gerbing (1982), a confirmatory factor analysis (CFA) was employed for the measurement scale validation. A covariance matrix of all measured variables was constructed and subject to a series of validity and reliability checks. A maximum likelihood estimation procedure using Analysis of Moment Structures (AMOS) version 18.0 was employed. The recommended cut off value for the goodness of fit indices was based on Hu and Bentler's (1999) recommendation. Although multiple indicators are more desirable, a construct with single indicator is still allowed in the use of Structural Equation Modeling (SEM) (Hair, Black Babin and Anderson, 2010) by fixing a priori error estimates on the single indicator and place theoretical constraint within the model (Hair et al., 2010). Following previous practices in the exercise domain, the exercise behavior indicator was given a fixed measurement error estimate of $40 \%$ (Courneya, Estabrooks and Nigg, 1997).

\subsection{Convergent Validity}

The CFA model was modified by examining the standardized residuals, modification indices and the standardized loading estimates (Hair, et al., 2010). The fit indices of the revised CFA (see Table 1) indicated that the specified model was a good fitting model. The chi-square value was significant due to the large sample size that often inflates Type I error (Bollen, 1990). An acceptable ratio for $\chi^{2} / \mathrm{df}$ value (i.e., less than 3.0) was achieved (Hair et al., 2010). Further, the fit indices for GFI, TLI and CFI were greater than .90 thresholds and the RMSEA value was well below the cut-off value of .06 for satisfactory model fit (Hu and Bentler, 1999).

To assess convergent validity, the loading of each observed indicators on its underlying latent construct was checked (Anderson and Gerbing, 1988). As shown in Table 1, each factor loading of the reflective indicators were statistically significant at 0.001 level, and all loadings exceeded the recommended level of 0.50 (Anderson and Gerbing, 1988). Overall, the variance extracted (VE) values for all main constructs exceeded the benchmark of .50 (Fornell and Larcker, 1981). Further, the composite reliabilities for all constructs were way above the .70 threshold (Nunnally, 1978). Overall, the requirements for loading estimates, variance extracted and composite reliability were met with adequate evidence of convergent validity demonstrated.

\subsection{Discriminant Validity}

Discriminant validity was assessed using a procedure advocated by Gaski and Nevin (1985) whereby a correlation between two scales that is lower than the reliability of each of those scales is taken as proof of good discriminant validity. The results (see Table 2) reveal that all the scales have reliabilities in excess of the correlations between them, indicating that each pair of constructs was indeed distinct. Taken together, a well fitting measurement model with adequate evidence of convergent and discriminant validity is established.

\subsection{Demographic Differences in Social Cognitive Factors and Exercise Behavior}

First, independent sample t-test was employed to examine the gender differences. A one-way analysis of variance (ANOVA) was then utilized to determine the significant differences in terms of age and education level with respect to their responses on the social cognitive and exercise behavior measures. When there were 
significant differences, Post Hoc Tests (Bonferroni) were examined to determine the particular group(s) which differed significantly within a significant overall one-way ANOVA (Hair et al., 2010).

\subsubsection{Gender Differences}

Table 3 presents the results of the mean comparisons between the gender groups. Overall, the differences in the group means were statistically significant in instrumental attitude, affective attitude, exercise intention, and exercise behavior. The findings concluded that male samples tended to have a higher score of both instrumental and affective attitude towards exercising as well as exercise intention compared to their female counterparts. The result also showed that male respondents tend to be more active in exercise activities.

In terms of attitude components, it appeared that males and females had considerable different evaluations about participating in exercise activities during leisure time. While Divine and Lepisto (2005) advocated that females tend to lead a healthier lifestyle than males, the present study found that male respondents have a more favorable instrumental and affective attitude towards exercise compared to female respondents. One may conclude that the gender effect may be dependent on the type of healthy lifestyle behaviors studied. For instance, although females might have a greater tendency to adopt healthy eating habits than males, but they may behave differently when it comes to exercise participation.

The present study reported that there was no significance in the gender difference in relation to the subjects' perception towards both the injunctive and descriptive norm. This is consistent with Symons Downs's, et al. (2006) study that found males and females to experience the same level of normative pressures from their 'significant others' to participate in exercise activities. Contrary to past studies that examined gender differences in the perception of control in the West (e.g., Sylvia-Bobiak and Caldwell, 2006; Symons Downs et al., 2006), the present study found no significant difference between males and females in terms of their perceived self-efficacy and controllability towards exercise participation. Possible explanations for these contradictory findings were the differences among studies in terms of samples used and cultural differences.

Corroborating with Symons Downs et al. (2006) and Brickell, Chatzisarantis and Pretty (2006), the present study found that male respondents demonstrated a greater intention to exercise compared to female respondents. It is possible that women living in the urban areas are mostly busy with career and care-giving roles for their family members, and consequently reducing their intention to exercise. Lastly, the finding revealed that males scored significantly higher than females on the measures of exercise behavior. This adds to the collection of other studies (e.g., Grzywacz and Marks, 2001; Rimal, 2002; Brickell, Chatzisarantis and Pretty, 2006) conducted in the West that supported this exercise pattern between males and females

\subsubsection{Age Group Differences}

Subjects were divided into three age groups i.e., 29 years old and younger, between 30 and 39 years old, and 40 to 55 years old. The one-way ANOVA results (see Table 4) showed significant age group differences in all the social cognitive factors studied (except for descriptive norm) as well as exercise intention and exercise behavior. The present study found that age had an association with the subjects' instrumental as well as affective attitude towards exercise participation whereby a significant different level of both instrumental and affective attitude was found for at least two of the three age groups. The Post-hoc test showed that subjects in the age group of ' 29 and below' were significantly scoring lower on both the instrumental and affective attitude compared to those in the older age group of ' 40 to 55'. This is inconsistent with Nigg, Lippke and Maddock's (2009) study that found no significant age difference in the global attitude construct. One possible reason could be the fact that respondents from different age group might have different concern for the health outcomes generated from exercising, and hence affecting their attitudes towards exercise differently.

With regards to the subjective norm components, there is no significant association between age and descriptive norm. However, the finding reported significant age differences in the injunctive norm measure whereby the age group of ' 30 to 39' tend to score lower on injunctive norm compared to those younger (i.e., below 29 years old) and older age group (i.e., 40 to 55 years old). Contradict to Nigg, Lippke and Maddock's (2009) study that found no significant age difference in the global PBC measure, the present study found age to be related to both perceived control and self-efficacy. That is, subjects in the younger age group of 'below 29' and '30 to 39' were significantly scoring lower on the perceived control measures compared to those in the older age group of ' 40 to 55'. Similar results were also reported for the association between age and perceived self-efficacy towards exercising. The results seem to make sense as older people might have lower barriers such as time and resources constraints that prevent them from exercising.

Next, the results showed significant age difference with respect to subjects' exercise intention and exercise behavior. The post-hoc group comparison found the mean score for age group of ' 40 to $55^{\text {' }}$ to be significantly higher than those subjects in the age group of ' 30 to 39'. This is in line with Divine and Lepisto's (2005) arguments that older people tend to maintain a healthier lifestyle. Possible explanation for the present finding could be that subjects in the age group of ' 40 to 49 ' are more health conscious as their age is catching up. It is also possible that they may have more health problems at this age and that made them want to maintain a healthy lifestyle by engaging in exercise activities. 
In terms of exercise participation, it was reported that subjects from the older age group of ' 40 to 55 ' were found to be significantly scoring higher on both the exercise intention and exercise behavior measures compared to the younger group. This further supports the notion that subjects in the age group of ' 40 to 49 ' tend to be more health conscious; as such they exercise regularly in order to stay healthy. While the present finding contradicts with Grzywacz and Marks (2001) and Piazza, Conrad and Wilbur (2001) which found that younger individuals exercise more regularly, it is nonetheless converge with Dychtwald and Gable (1990) who reported that the proportion of baby boomers who regularly participate in exercise is twice that of the rest of the population.

\subsubsection{Education Level Differences}

The one-way ANOVA results (see Table 5) showed that the subjects' education level exerts an influence on instrumental attitude, perceived control as well as exercise intention and exercise behavior. Specifically, it was found that the lower education group (i.e., 'STPM/HSC/A-Level \& below') scored lower on instrumental attitude scale than those in the group with higher education level (i.e., 'College diploma/certificate/vocational' and 'University or Professional Degree'). This finding seems to be in line with the notion that education has a positive association with health (Ross and $\mathrm{Wu}, 1996)$. One possible reason for this association is that education might influence a person's ability in understanding and interpreting health information regarding the importance and benefits of regular exercise (Grzywacz and Marks, 2001). In this instance, the way a person interprets health information does affect their instrumental attitude towards exercising. Hence, it is not surprising that the present study found subjects who have attained a higher education have also formed a more favorable instrumental attitude toward exercising. The associations between education level and both the subjective norm components were found to be insignificant, indicating that subjects from different education groups seem to experience a similar degree of injunctive and descriptive normative influence.

Although the education level differences in perceived control were found to be significant, but its association with self-efficacy was insignificant. Specifically, subjects in the lower education level group (i.e., 'STPM/HSC/A-Level \& below') were found to have a lower perception of control towards exercise compared to those in the education group of 'College diploma/certificate/vocational' and 'University/professional degree \& above'. Grzywacz and Marks (2001) argued that a person's socio-economic background can possibly affect the allocation of resources, opportunities, and constraints that may influence a person's health behaviors. This may be true as people who are more educated may have a higher chance to: (1) secure a job in an organization with exercise facilities; (2) have a higher salary to join fitness clubs and / or buy sports equipment; (3) stay in a safer neighborhood that allows jogging and walking; and possibly (4) live in a condominium with facilities (Ross and $\mathrm{Wu}, 1996)$.

Converge with the findings for the association between education level and perceived control, it was reported that subjects of higher education level have a greater intention to engage in exercise activities compared to subjects who are less educated. This is also reflected in the exercise behavior measures whereby respondents who possess a university degree and above exercise more regularly compared to those less educated group (i.e., 'STPM/HSC/A-Level \& below'). This finding, though incongruent with Mohd Nordin's et al. (2003) study that found no significant association between education level and exercise behavior, it was, however, in accordance with previous studies that demonstrated a positive link between education level and exercise behavior (e.g., Grzywacz and Marks, 2001; Rimal, 2002).

\section{Managerial Implications}

There are numerous factors that can influence individual exercise behavior, for instance, demographic, psychological, environmental, cultural and family influence (Kerner and Grossman, 2001). Among these factors, demographic variables are often overlooked in the investigation of exercise behavior. The choices made by an individual concerning exercise and fitness activities are a form of consumer behavior. Analyzing the association between demographic variables, social cognition and exercise behavior helps to build a better understanding of complex consumer behavior. Theoretically, this study contributes by reducing the contention that there is dearth of exercise research in marketing literature and in the non-western context. Armed with this knowledge, marketing practitioners can then find potential market opportunities and determine the appropriate marketing mix in order to develop practical and effective marketing strategies.

Most of the past TPB studies relied on homogeneous group (e.g., undergraduate students) with a strong focus on youth and adolescent as a sample population. One sampling problem associated with such a relatively homogenous group is that the results may not be generalized to the larger population (Hagger, Anderson, Kyriakaki and Darkings, 2007). The present study was carried out in Malaysia using general adult population as respondents. It is believed that adults as opposed to adolescent will be able to provide more accurate, realistic and stable view points. Methodologically, this study contributes to the existing body of knowledge by examining the relationships between variables of interest with a different sample.

The trend for healthier living among urban Malaysians will have an impact on consumer spending on core healthcare products and medical services. This influence extend to other sectors such as food beverages, leisure and recreation, organic food, exercise machines, sports equipment, vitamins and dietary supplements, and 
over-the-counter drugs. This evolving trend has strong implications on marketing planning and implementation. However, to simply apply a common marketing approach to all customers without looking at customer characteristics can be disastrous. The present study found that demographic variables such as gender, age, and education have an association with several social cognitive factors and exercise behavior. Knowing whether the different demographic groupings exhibit different responses on the social cognitive and exercise behavior could have considerable marketing implications. For instance, based on such information, health care marketers are in a much better position for market planning and for the development of current or new offerings, and development of appropriate communication strategies. Food manufacturers and retailers could also use such information to determine the appropriateness of product, distribution, and promotional strategies that target at these segments.

More specifically, the health club and various fitness programs have spread across urban areas in Malaysia. Today, fitness clubs in Malaysia are becoming a lifestyle choice. Essentially, the fitness industry is moving towards a one-stop, holistic wellness centre concept, appealing to a broader market rather than hard physical exercise. This shift of exercise pattern has implications for the marketers and advertisers. Marketers start to embrace innovative marketing strategies and finding ways to differentiate themselves in this competitive market. For instance, the present study found that the lower score of females with respect to their instrumental and affective attitude, exercise intention and behavior which might be due to the busy schedules that many working women living in urban areas have in managing their full-time work, childcare, and housekeeping responsibilities. To target this segment, health club and various fitness program operators should pay greater attention to ensure easy accessibility and convenience for service delivery such as having longer operating hours, easy and free parking and strategic location.

The pressure of escalating costs of public health care has been a major concern for people and the government. Despite various government efforts in health promotion and public awareness of the potential risks associated with sedentary lifestyle, the exercise participation among Malaysians is relatively low. Gaining long-term, effective and consistent behavioral change aimed at increasing public's exercise participation is a very challenging task for public policy makers. It is hoped that the present findings are not only useful for marketing practitioners, public policy officials and health professionals may also use such information in designing effective strategies and interventions seeking to increase the general public exercise participation. The present study provides a base for future research on not just exercise participation, but also extended to other healthy lifestyle behaviors.

\section{Limitations and Suggestions for Future Research}

The limitations of the present study which suggested a number of areas for concern, point to several avenues for further research. First, although subjects were assured of anonymity and confidentiality, potential social desirability associated with self-report measures may have artificially inflated the observed relationship. Also, there is a concern regarding a common method variance which interpret the correlations between measures derived from a single-source self-report data (Summers, 2001). However, most researchers adopting Ajzen's model still rely largely on self-report data. In the exercise domain, self-report is considered the most common and practical approach for its consistent reliability and validity (see Godin and Shephard, 1985; Godin, Jobin and Bouillon, 1986). Self-report measure was adopted as it is less costly and easily administered, and they have been shown to be a reliable and valid approach for collecting information regarding exercise behavior. However, further research may consider more objective measures such as fitness class attendance or activity.

Next, the present study only considers gender, age, and education level. Other demographic variables such as ethnicity and income level that might be associated with social cognition and exercise behavior should be considered in future research. Further, this study based on a sample from Klang Valley areas given that exercise is an urban phenomenon. Hence, results are not generalized to a larger population. Since there might be differences in terms of social and behavioral aspects between the rural and the urban dweller, future research should also replicate the study to other states in Malaysia. Lastly, this study focused primarily on exercise behavior. The attempt to investigate other consumer healthy lifestyle behaviors such as healthy eating, tobacco-free lifestyle, substance use, health preventive practices, and weight control is encouraged to explore more comprehensive aspects of healthy lifestyle.

\section{References}

"Health Ministry seeks to trim down obesity cases". (2010). The Star. December 9, 2010. [Online] Available: http://thestar.com.my/news/story.asp?file=/2010/12/9/nation/7587999\&sec=nation (March 2, 2011)

Adams, T. B., \& Mowen, J. C. (2005). Identifying the personality characteristics of healthy eaters and exercisers: A hierarchical model approach. Health Marketing Quarterly, 23 (1), 21-42. Retrieved March 5, 2010, from the Taylor \& Francis Journals. doi:10.1300/J026v23n01_03, http://dx.doi.org/10.1300/J026v23n01_03

Ajzen, I. (1991). The theory of planned behavior. Organizational Behavior and Human Decision Processes, 50 (2), 179-212. doi:10.1016/0749-5978(91)90020-T, http://dx.doi.org/10.1016/0749-5978(91)90020-T 
Anderson, J. C., \& Gerbing, D. W. (1982). Some methods for respecifying measurement models to obtain unidimensional construct measures. Journal of Marketing Research, 19 (4), 453-460. doi:10.2307/3151719, http://dx.doi.org/10.2307/3151719

Anderson, J. C., \& Gerbing, D. W. (1988). Structural equation modeling in practice: A review and recommend two-step approach. Psychological Bulletin, 103 (3), 411-423.

Andres, L. (2006). Exercise? Not us, say youth. New Straits Times, October 10, p. 17.

Armitage, C. J., \& Christian, J. (2003). From attitudes to behavior: Basic and applied research on the theory of planned behavior. Current Psychology: Developmental, Learning, Personality, Social, 22 (3), 187-195. doi:10.1007/s12144-003-1015-5, http://dx.doi.org/10.1007/s12144-003-1015-5

Armitage, C. J., \& Conner, M. (2001). Efficacy of the theory of planned behavior: A meta-analytic review. The British Journal of Social Psychology, 40, 471-499. doi:10.1348/014466601164939, http://dx.doi.org/10.1348/014466601164939

Biddle, S. J. H., \& Nigg, C. R. (2000). Theories of exercise behavior. International Journal of Sport Psychology, 31 (2), 290-304. [Online] Available: www.scopus.com. (March 5, 2011)

Bollen, K. A. (1990). Overall fit in covariance structural models: Two types of sample size effects.

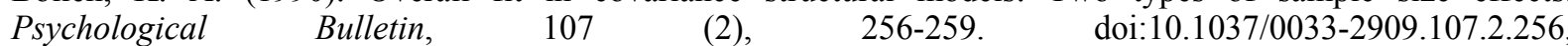
http://dx.doi.org/10.1037/0033-2909.107.2.256

Bolton, L. E., Reed, A., Volpp, K. G., \& Armstrong, K. (2008). How does drug and supplement marketing affect a healthy lifestyle? Journal of Consumer Research, 34 (5), 71-724. doi:10.1086/521906, http://dx.doi.org/10.1086/521906

Bond, K. A., \& Batey, J. (2005). Running for their lives: A qualitative analysis of the exercise experience of female recreational runners. Women in Sport and Physical Activity Journal, 14 (2), 69-782.

Brickell, T. A., Chatzisarantis, N. L. D., \& Pretty, G. M. (2006). Using past behavior and spontaneous implementation intentions to enhance the utility of the theory of planned behavior in predicting exercise. British Journal of Health Psychology, 11 (2), 249-262. doi:10.1348/135910705X52471, http://dx.doi.org/10.1348/135910705X52471

Calder, B. J., Philips, L. W., \& Tybout, A. M. (1982). The concept of external validity. Journal of Consumer Research, 9 (3), 240-244. doi:10.1086/208920, http://dx.doi.org/10.1086/208920

Consumer Health - Malaysia. (2010). Euromonitor International: Country Market Insight. Euromonitor International Databases. [Online] Available: http://www.euromonitor.com (February 12, 2011)

Courneya, K. S., \& Hellsten, L. A. M. (1998). Personality correlates of exercise behavior, motives, barriers and preferences: An application of the five-factor model. Personality and Individual Differences, 24 (5), 625-633. doi:10.1016/S0191-8869(97)00231-6, http://dx.doi.org/10.1016/S0191-8869(97)00231-6

Courneya, K. S., Bobick, T. M., \& Schinke, R. J. (1999). Does the theory of planned behavior mediate the relation between personality and exercise behavior. Basic and Applied Social Psychology, 21 (4), 317-324.

Courneya, K. S., Estabrooks, P. A., \& Nigg, C. R. (1997). A simple reinforcement strategy for increasing attendance at a fitness facility. Health and Education and Behavior, 24 (6), 708-715.

Divine, R. L., \& Lepisto, L. (2005). Analysis of the healthy lifestyle consumer. Journal of Consumer Marketing, 22 (5), 275-283. Retrieved August 26, 2010, from the Emerald Group Publishing Limited. doi:10.1108/07363760510611707, http://dx.doi.org/10.1108/07363760510611707

Dychtwald, K., \& Gable, G. (1990). Portrait of a changing consumer. Business Horizons, January-February, 33 (1), 62-73. Retrieved December 30, 2010, from the Business Source Premier Database.

Fontenelle, S. M., \& Zinkhan, G. M. (1993). Gender differences in the perception of leisure: A conceptual model. Advances in Consumer Research, 20 (1), 534-540.

Fornell, C., \& Larcker, D. F. (1981). Evaluating structural equations with unobservable variables and measurement error. Journal of Marketing Research, 18 (1), 39-50. doi:10.2307/3151312, http://dx.doi.org/10.2307/3151312

Gaski, J. F., \& Nevin, J. R. (1985). The differential effects of exercised and unexercised power sources in a marketing channel. Journal of Marketing Research, 22, 130-142. doi:10.2307/3151359, http://dx.doi.org/10.2307/3151359

Godin, G., \& Shephard, R. J. (1985). A simple method to assess exercise behavior in the community. Canadian Journal of Applied Sport Sciences, 10 (3), 141-146. [Online] Available: www.scopus.com. (March 2, 2011)

Godin, G., Jobin, J., \& Bouillon, J. (1986). Assessment of leisure time exercise behavior by self-report: A concurrent validity study. Canadian Journal of Public Health, 77 (5), 359-361. 
Grzywacz, J. G., \& Marks, N. F. (2001). Social inequalities and exercise during adulthood: Toward an ecological perspective. Journal of Health and Social Behavior, 42 (2), 202-220.

Hagger, M. S., \& Chatzisarantis, N. L. D. (2005). First-and higher-order models of attitude, normative influence, and perceived behavioural control in the theory of planned behaviour. British Journal of Social Psychology, 44 (4), 513-535.

Hagger, M. S., Anderson, M., Kyriakaki, M., \& Darkings, S. (2007). Aspects of identity and their influence on intentional behavior: Comparing effects for three health behaviors. Personality and Individual Differences, 42, 355-367. doi:10.1016/j.paid.2006.07.017, http://dx.doi.org/10.1016/j.paid.2006.07.017

Hair, J. F., Black, W. C., Babin, B. J., \& Anderson, R. E. (2010). Multivariate Data Analysis. $7^{\text {th }}$ edition. Upper Saddle River, New Jersey: Prentice Hall.

Health Facts in Malaysia (2009). Planning and Development Division. Ministry of Health Malaysia. Malaysia. [Online] Available: http://www.moh.gov.my/images/gallery/stats/heal_fact/healthfact_L_2009.pdf (February 13, 2011)

Hu, L., \& Bentler, P. M. (1999). Cut off criteria for fit indexes in covariance structure analysis: Conventional criteria versus new alternatives. Structural Equation Modeling, 6 (1), 1-55. [Online] Available: www.scopus.com (November 6, 2010) doi:10.1080/10705519909540118, http://dx.doi.org/10.1080/10705519909540118

Johnson, D. (1998). Tracking fitness: From fashion fad to health trend. The Futurist, 32 (4), 8 (3/4p).

Ka He, M. D., Kramer, E., Houser, R. F., Chomitz, V. R., \& Hacker, K. A. (2004). Defining and understanding healthy lifestyles choices for adolescents. Journal of Adolescent Health, 35 (1), 26-33. doi:10.1016/j.jadohealth.2003.09.004, http://dx.doi.org/10.1016/j.jadohealth.2003.09.004

Kerner, M. S., \& Grossman, A. H. (2001). Scale construction for measuring attitude, beliefs, perception of control, and intention to exercise. Journal of Sports Medicine and Physical Fitness, 40 (1), 124-131. [Online] Available:

http://ezproxy.lib.monash.edu.au/login?url=http://proquest.umi.com.ezproxy.lib.monash.edu.au/pqdweb?did=75 436659\& $\mathrm{sid}=15 \& \mathrm{Fmt}=4 \&$ clientId $=16397 \& \mathrm{RQT}=309 \& \mathrm{VName}=\mathrm{PQD}($ March 2, 2011)

Marks, G. R., \& Lutgendorf, S. K. (1999). Perceived health competence and personality factors differentially predict health behaviors in older adults. Journal of Aging and Health, 11 (2), 221-239. Retrieved December 30, 2011. doi:10.1177/089826439901100205, http://dx.doi.org/10.1177/089826439901100205

Mohd Nordin, N. A. M., Shamsuddin, K., Jamaludin, J., \& Zulkafli, N. H. (2003). Work and home physical activity profile of women workers in an electronics factory in the Klang Valley, Malaysia. Women's Health and Urban Life: An International and Interdisciplinary Journal, 2 (2), 5-20.

Morris, M. G., \& Venkatesh, V. (2000). Age differences in technology adoption decisions: Implications for a changing workforce. Personnel Psychology, 53 (2), 375-403. doi:10.1111/j.1744-6570.2000.tb00206.x, http://dx.doi.org/10.1111/j.1744-6570.2000.tb00206.x

Ngui, Y. K (2005). Fighting the flab. Malaysian Business. April 1, p. 46.

Nies, M. A., \& Kershaw, T. C. (2002). Psychosocial and environmental influences on physical activity and health outcomes in sedentary women. Journal of Nursing Scholarship, 34 (3), 243-249.

Nigg, C. R., Lippke, S., \& Maddock, J. E. (2009). Factorial invariance of the theory of planned behavior applied to physical activity across gender, age, and ethnic groups. Psychology of Sport and Exercise, 10, 219-225. doi:10.1016/j.psychsport.2008.09.005, http://dx.doi.org/10.1016/j.psychsport.2008.09.005

Nunnally, J. C. (1978). Psychometric Theory, $2^{\text {nd }}$ edition. New York: McGraw-Hill.

Omar, Z. A. (2002). Diet, physical exercise and health: Are we doing enough?. NCD Malaysia, 1 (3), 2-3.

Paluska, S. A., \& Schwenk, T. L. (2000). Physical activity and mental health: Current concepts. Sports Medicine, 29 (3), 167-180. doi:10.2165/00007256-200029030-00003, http://dx.doi.org/10.2165/00007256-200029030-00003

Pang, H. Y. (2006). Getting' em hale and hearty. The Star. Star Special (Ministry of Health), December 21, p. SP2.

Piazza, J., Conrad, K., \& Wilbur, J. (2001). Exercise behavior among female occupational health nurses influences of self efficacy, perceived health control, and age. American Association of Occupational Health Nurses Journal, 49 (2), 79-86.

Rhodes, R. E., \& Courneya, K. S. (2003). Investigating multiple components of attitude, subjective norm, and perceived control: An examination of the theory of planned behavior in the exercise domain. British Journal of Social Psychology, $42 \quad$ (1), 129-146. doi:10.1348/014466603763276162, http://dx.doi.org/10.1348/014466603763276162 
Rhodes, R. E., Blanchard, C. M., \& Matheson, D. H. (2006). A multicomponent model of the theory of planned behavior. British Journal of Health Psychology, 11 (1), 119-137. doi:10.1348/135910705X52633, http://dx.doi.org/10.1348/135910705X52633

Rhodes, R. E., Blanchard, C. M., Matheson, D. H., \& Coble, J. (2006). Disentangling motivation, intention, and planning in the physical activity domain. Psychology of Sport and Exercise, 7 (1), 15-27. doi:10.1016/j.psychsport.2005.08.011, http://dx.doi.org/10.1016/j.psychsport.2005.08.011

Rimal, A. (2002). Association of nutrition concerns and socioeconomic status with exercise habit. International Journal of Consumer Studies, 26 (4), 322-327.

Ross, C. E., \& Wu, C. L. (1996). Education, age, and the cumulative advantage in health. Journal of Health and Social Behavior, 37 (1), 104-120. doi:10.2307/2137234, http://dx.doi.org/10.2307/2137234

Rütten, A., Röger, U., Abu-Omar, K., \& Frahsa, A. (2009). Assessment of organizational readiness for health promotion policy implementation: test of a theoretical model. Health Promotion International, 24, 243-251. doi:10.1093/heapro/dap016, http://dx.doi.org/10.1093/heapro/dap016

Steptoe, A., Wardle, J., Vinck, J., Tuomisto, M., Holte, A., \& Wichstrøm, L. (1994). Personality and attitudinal correlates of healthy and unhealthy lifestyles in young adults. Psychology and Health, 9 (5), 331-343. doi:10.1080/08870449408407492, http://dx.doi.org/10.1080/08870449408407492

Summers, J. O. (2001). Guidelines for conducting research and publishing in marketing: From conceptualization through the review process. Journal of the Academy of Marketing Science, 29 (4), 405-415. doi:10.1177/03079450094243, http://dx.doi.org/10.1177/03079450094243

Sylvia-Bobiak, S., \& Caldwell, L. L. (2006). Factors related to physically active leisure among college students. Leisure Sciences, 28 (1), 73-89. Retrieved December 30, 2010, from the Business Source Premier Database. doi:10.1080/01490400500332728, http://dx.doi.org/10.1080/01490400500332728

Symons Downs, D., Graham, G. M., Yang, S., Bargainier, S., \& Vasil, J. (2006). Youth exercise intention and past exercise behavior: Examining the moderating influences of sex and meeting exercise recommendations. Research Quarterly for Exercise and Sport, 77 (1), 91-99.

The Malaysian Pharmaceutical Industry. (2011). Malaysian Organisation of Pharmaceutical Industries, Malaysia. [Online] Available: http://www.mopi.org.my (January, 2011)

Wilson, P. M., Rodgers, W. M., Fraser, S. N., \& Murray, T. C. (2004). Relationships between exercise regulations and motivational consequences in university students. Research Quarterly for Exercise and Sport, 75 (1), 81-91.

Table 1. Confirmatory Factor Analysis for Convergent Validity

\begin{tabular}{|l|c|c|c|c|}
\hline Construct & No. of Items & Item Loadings & $\begin{array}{c}\text { Construct } \\
\text { Reliability }\end{array}$ & $\begin{array}{c}\text { Variance } \\
\text { Extracted }\end{array}$ \\
\hline Instrumental Attitude & 4 & $0.713-0.803^{* * *}$ & 0.841 & 0.569 \\
\hline Affective Attitude & 4 & $0.772-0.842^{* * *}$ & 0.879 & 0.647 \\
\hline Injunctive Norm & 4 & $0.660-0.771^{* * *}$ & 0.803 & 0.506 \\
\hline Descriptive Norm & 4 & $0.772-0.918^{* * *}$ & 0.908 & 0.715 \\
\hline Perceived Control & 4 & $0.624-0.904^{* * *}$ & 0.861 & 0.613 \\
\hline Perceived Self-efficacy & 4 & $0.642-0.865^{* * *}$ & 0.840 & 0.572 \\
\hline Exercise Intention & 6 & $0.729-0.815^{* * *}$ & 0.900 & 0.601 \\
\hline
\end{tabular}

Note:

a. $\quad$ Model fit indices (Revised Model): $\chi^{2}=808.20, \chi^{2} / \mathrm{df}=1.986$, GFI $=0.905, \mathrm{TLI}=0.953, \mathrm{CFI}=0.959$, RMSEA $=0.044$

b. Chi-square $\left(\chi^{2}\right)$; degree of freedom (df); Goodness-of-fit Index (GFI); Tucker-Lewis Index (TLI), Comparative Fit Index (CFI), Parsimonious Normed Fit Index (PNFI), and Root Mean Square Error of Approximation (RMSEA).

$* * * \mathrm{p}<0.001$ 
Table 2. Correlations between Scales

\begin{tabular}{|l|c|c|c|c|c|c|c|c|}
\hline Factor & $\mathbf{B E H}$ & INT & IA & AA & IN & DN & PC & SE \\
\hline BEH & $-^{\mathrm{a}}$ & & & & & & & \\
\hline INT & $.591^{* *}$ & $\mathbf{0 . 9 0 0}$ & & & & & & \\
\hline IA & $.453^{* *}$ & $.837 * *$ & $\mathbf{0 . 8 4 1}$ & & & & & \\
\hline AA & $.499^{* *}$ & $.848^{* *}$ & $.768^{* *}$ & $\mathbf{0 . 8 7 9}$ & & & & \\
\hline IN & $.277^{* *}$ & $.520^{* *}$ & $.602^{* *}$ & $.451^{* *}$ & $\mathbf{0 . 8 0 3}$ & & & \\
\hline DN & $.291^{* *}$ & $.326^{* *}$ & $.293^{* *}$ & $.305^{* *}$ & $.494^{* *}$ & $\mathbf{0 . 9 0 8}$ & & \\
\hline PC & $.460^{* *}$ & $.643^{* *}$ & $.509^{* *}$ & $.574^{* *}$ & $.356^{* *}$ & $.297^{* *}$ & $\mathbf{0 . 8 6 1}$ & \\
\hline SE & $.530^{* *}$ & $.796^{* *}$ & $.700^{* *}$ & $.665^{* *}$ & $.561^{* *}$ & $.392^{* *}$ & $.745^{* *}$ & $\mathbf{0 . 8 4 0}$ \\
\hline
\end{tabular}

Note: $\mathrm{BEH}=$ Exercise Behaviour; INT = Exercise Intention; IA = Instrumental Attitude; AA = Affective Attitude; IN = Injunctive Norm; DN = Descriptive Norm; PC = Perceived Control; SE $=$ Self-efficacy; ${ }^{\text {a }}$ single-item measure

**Correlation is significant at $\mathrm{p}<.01$

Table 3. Gender differences with respect to social cognitive factors

\begin{tabular}{|l|c|c|c|c|}
\hline \multirow{2}{*}{ Factors } & \multicolumn{2}{|c|}{ Mean (Std. Dev.) $^{\mathrm{a}}$} & \multirow{2}{*}{ t-value $^{*}$ Significance $^{\mathrm{b}}$} \\
\cline { 2 - 4 } & Male (n=256) & Female (n=256) & & \\
\hline Instrumental Attitude & $6.01(0.705)$ & $5.88(0.776)$ & 2.002 & $.046^{*}$ \\
\hline Affective Attitude & $5.70(0.763)$ & $5.52(0.869)$ & 2.485 & $.013^{*}$ \\
\hline Injunctive Norm & $5.21(1.013)$ & $5.19(0.970)$ & .290 & .772 \\
\hline Descriptive Norm & $4.44(1.200)$ & $4.29(1.139)$ & 1.539 & .124 \\
\hline Perceived Control & $5.14(1.023)$ & $5.01(1.048)$ & 1.451 & .147 \\
\hline Self-efficacy & $5.36(0.870)$ & $5.27(0.855)$ & 1.140 & .255 \\
\hline Exercise Intention & $5.55(0.816)$ & $5.35(0.903)$ & 2.618 & $.009^{* *}$ \\
\hline Exercise Behavior ${ }^{\mathrm{C}}$ & $25.10(12.42)$ & $20.33(11.39)$ & 4.528 & $.000^{* * *}$ \\
\hline
\end{tabular}

Note: ${ }^{\mathrm{a}}$ Measured on 7-point scale whereby higher scores represent greater agreement with the attributes; ${ }^{\mathrm{b}}$ Level of significance using t-tests; ${ }^{\mathrm{c}}$ open scale ranges from 3 to 73

$* \mathrm{p}<.05 ; * * \mathrm{p}<.01 ; * * * \mathrm{p}<.001$

Table 4. Age Group Differences with respect to social cognitive factors

\begin{tabular}{|c|c|c|c|c|c|c|}
\hline \multirow[t]{2}{*}{ Factors } & \multicolumn{3}{|c|}{ Age Group (Mean) $^{a}$} & \multirow[t]{2}{*}{$\mathbf{F}$} & \multirow[t]{2}{*}{ Sig. ${ }^{b}$} & \multirow{2}{*}{$\begin{array}{l}\text { Group } \\
\text { Comparison } \\
\text { (Bonferroni) }\end{array}$} \\
\hline & $\begin{array}{l}\leq 29 \text { G1 } \\
(n=237)\end{array}$ & $\begin{array}{c}30-39 \text { G2 } \\
(n=137)\end{array}$ & $\begin{array}{c}40-55 \mathbf{G 3} \\
(\mathrm{n}=138)\end{array}$ & & & \\
\hline Instrumental Attitude & 5.93 & 5.82 & 6.11 & 5.32 & $.005 * *$ & $\mathrm{G} 1<\mathrm{G} 3, \mathrm{G} 2<\mathrm{G} 3$ \\
\hline Affective Attitude & 5.63 & 5.43 & 5.78 & 6.32 & $.002 * *$ & $\mathrm{G} 2<\mathrm{G} 3$ \\
\hline Injunctive Norm & 5.26 & 5.01 & 5.29 & 3.66 & $.026^{*}$ & $\mathrm{G} 2<\mathrm{G} 1, \mathrm{G} 2<\mathrm{G} 3$ \\
\hline Descriptive Norm & 4.38 & 4.32 & 4.40 & 0.17 & .842 & Not significant \\
\hline Perceived Control & 5.07 & 4.82 & 5.34 & 9.04 & $.000 * * *$ & $\mathrm{G} 1<\mathrm{G} 3, \mathrm{G} 2<\mathrm{G} 3$ \\
\hline Self-efficacy & 5.30 & 5.15 & 5.50 & 5.74 & $.003 * *$ & $\mathrm{G} 2<\mathrm{G} 3$ \\
\hline Exercise Intention & 5.43 & 5.30 & 5.63 & 5.29 & $.005 * *$ & $\mathrm{G} 2<\mathrm{G} 3$ \\
\hline Exercise Behavior $^{\mathrm{C}}$ & 23.64 & 18.78 & 25.02 & 10.80 & $.000 * * *$ & $\mathrm{G} 2<\mathrm{G} 1, \mathrm{G} 2<\mathrm{G} 3$ \\
\hline
\end{tabular}

Note: ${ }^{a}$ Measured on 7-point scale whereby higher scores represent greater agreement with the attributes; ${ }^{b}$ Level of significance using one-way ANOVA; ${ }^{c}$ open scale ranges from 3 to 73

$* \mathrm{p}<.05 ; * * \mathrm{p}<.01 ; * * * \mathrm{p}<.001$ 
Table 5. Education Group Differences with respect to social cognitive factors

\begin{tabular}{|c|c|c|c|c|c|c|}
\hline \multirow[t]{2}{*}{ Constructs } & \multicolumn{3}{|c|}{ Education Level Group (Mean) $^{a}$} & \multirow[t]{2}{*}{$\mathbf{F}$} & \multirow[t]{2}{*}{ Sig. $^{b}$} & \multirow{2}{*}{$\begin{array}{l}\text { Group } \\
\text { Comparison } \\
\text { (Bonferroni) }\end{array}$} \\
\hline & $\begin{array}{c}\mathrm{G} 1 \\
(\mathrm{n}=179)\end{array}$ & $\begin{array}{c}\text { G2 } \\
(151)\end{array}$ & $\begin{array}{c}\text { G3 } \\
(\mathrm{n}=182)\end{array}$ & & & \\
\hline Instrumental Attitude & 5.78 & 6.01 & 6.06 & 7.558 & $.001 * *$ & $\mathrm{G} 1<\mathrm{G} 2, \mathrm{G} 1<\mathrm{G} 3$ \\
\hline Affective Attitude & 5.55 & 5.70 & 5.60 & 1.366 & .256 & Not significant \\
\hline Injunctive Norm & 5.13 & 5.20 & 5.27 & 984 & .375 & Not significant \\
\hline Descriptive Norm & 4.26 & 4.42 & 4.42 & 1.098 & .334 & Not significant \\
\hline Perceived Control & 5.12 & 5.39 & 5.43 & 6.872 & $.001 * *$ & $\mathrm{G} 1<\mathrm{G} 2, \mathrm{G} 1<\mathrm{G} 3$ \\
\hline Self-efficacy & 4.93 & 5.16 & 5.16 & 2.785 & .063 & Not significant \\
\hline Exercise Intention & 5.27 & 5.57 & 5.53 & 6.200 & $.002 * *$ & $\mathrm{G} 1<\mathrm{G} 2, \mathrm{G} 1<\mathrm{G} 3$ \\
\hline Exercise Behavior $^{c}$ & 20.69 & 23.58 & 23.98 & 3.896 & $.021 *$ & $\mathrm{G} 1<\mathrm{G} 3$ \\
\hline
\end{tabular}

Note 1: ${ }^{\mathrm{a}}$ Measured on 7-point scale whereby higher scores represent greater agreement with the attributes; ${ }^{\mathrm{b}}$ Level of significance using one-way ANOVA; ${ }^{\circ}$ open scale ranges from 3 to 73

Note 2: STPM/HSC/A-Level \& below (G1); College diploma/certificate/vocational (G2);

University/professional degree $\&$ above (G3).

$* \mathrm{p}<.05 ; * * \mathrm{p}<.01 ; * * * \mathrm{p}<.001$ 